prospective multicenter analysis. Spine. 2013;38(13):E803-812. doi:10.1097/BRS.0b013e318292b7b9

3. Schwab F, Ungar B, Blondel B, et al. Scoliosis Research Society-Schwab adult spinal deformity classification: a validation study. Spine. 2012;37(12):1077-1082. doi:10.1097/BRS.0b013e31823e15e2

4. Ailon $T$, Smith JS, Shaffrey $C I$, et al. Degenerative Spinal Deformity. Neurosurgery. 2015;77 Suppl 4:S75-91. doi:10.1227/ NEU.0000000000000938

5. Ha AS, Hong DY, Luzzi AJ, et al. Minimum 2Year Analysis of S2-Alar-Iliac Screw Fixation for Adult Spinal Deformity. Glob Spine J. Published online January 7, 2021:2192568220984478. doi:10.1177/2192568220984478
6. Smith EJ, Kyhos J, Dolitsky R, Yu W, O'Brien J. S2 Alar Iliac Fixation in Long Segment Constructs, a Two- to Five-Year Follow-up. Spine Deform. j.jspd.2017.05.004

7. Fujimori $\mathbf{T}$, Inoue $\mathbf{S}$, Le $\mathbf{H}$, et al. Long fusion from sacrum to thoracic spine for adult spinal deformity with sagittal imbalance: upper versus lower thoracic spine as site of upper instrumented vertebra. Neurosurg Focus. 2014;36(5):E9. doi:10.3171/2014.3.FOCUS13541

8. Matsumura A, Namikawa $T$, Kato $M$, et al. Posterior corrective surgery with a multilevel transforaminal lumbar interbody fusion and a rod rotation maneuver for patients with degenerative lumbar kyphoscoliosis. J Neurosurg Spine. 2017;26 (2):150-157. doi:10.3171/2016.7.SPINE16172.

\title{
KẾT QUẢ PHẪU THUÂT TẠO HÌNH BIẾN DẠNG THÁP MŨI DI CHỨNG CHẤN THƯƠNG
}

\section{TÓM TẮT}

Mục tiêu: Đánh giá kết quả phẫu thuật điều tri biến dạng tháp mũi do di chứng chấn thương. Đối tượng nghiên cứu: 20 bệnh nhân được chẩn đoán biến dạng tháp mũi di chứng chấn thương trên 3 tháng bằng khám lâm sàng và chụp phim (X-quang hoặc CT). Được can thiệp phẫu thuật tạo hình biến dạng tháp mữi và tự nguyện tham gia nghiên cứu. Kết quả: Tuổi trung bình 31.15 tuổi. Biến dang mũi: hình yên ngựa $80 \%$, lệch vẹo $45 \%$. Phẫu thuật: chỉnh hình xương mũi (cắt xương + mài gồ) $60 \%$, tao hình độn sống mũi $85 \%$ trong đó chất liệu chủ yếu là sụn sườn tự thân $75 \%$; tạo hình đâu mũi $75 \%$. Các chỉ số nhân trắc sau phẫu thuật: có cải thiện đáng kể là tỉ lệ hình chiếu đâu mũi/chiểu dài sống mũi (tữ 0.638 lên 0.749 ) và góc mũi trán (từ $96^{\circ}$ lên $104.3^{\circ}$ ) với $\mathrm{p}<0,01$; cải thiện nhưng không đáng kể là độ lệch vẹo và góc trụ mũi môi. Kết luận: Kết quả nhân trắc sau phẫu thuật phù hợp với đối tượng nghiên cứu chủ yếu là biến dạng yên ngựa và có ý nghĩa về mặt thẩm mỹ.

Tư khóa: Biến dạng mũi di chứng chấn thương; Biến dạng mũi yên ngựa; Phẫu thuật tạo hình tái cấu trúc mũii.

\section{SUMMARY \\ RESULTS OF SURGICAL DEFORMITY RHINOPLASTY AFTER TRAUMA}

Objectives: To evaluate the results of surgical deformity rhinoplasty after trauma. Study design:

\footnotetext{
${ }^{1}$ Bệnh viện Hồng Ngọc,

²Bệnh viện Trung Ương Quân Đội 108

Chịu trách nhiệm chính: Bùi Tuấn Anh

Email: buituananh1612@gmail.com

Ngày nhận bài: 20.9.2021

Ngày phản biện khoa học: 15.11.2021

Ngày duyệt bài: 24.11.2021
}

Bùi Tuấn Anh"1, Vũ Ngọc Lâm²

Cross - sectional descriptive study. Patients: 20 patients were diagnosed with nasal deformities after 3 months of trauma by clinical examination and film (Xray or Computed tomography). Received surgical intervention to shape the nasal pyramid deformity and volunteered to participate in the study. Results: Mean age 31.15 years old. Nose deformity: saddle shape $80 \%$, deviated $45 \%$. Surgery: $60 \%$ Mid-Vault surgery (Hump reduction and Osteotomy), 85\% Dorsal augmentation, $75 \%$ of which are autologous costal cartilage, $75 \%$ tip plasty. Anthropometric indices after surgery: there was a significant improvement in the ratio of the tip projection-to-nasal length (from 0.638 to 0.749 ) and the nasofrontal angle (from $96^{\circ}$ to $104.3^{\circ}$ ) with $\mathrm{p}<0.01$; but not significantly improved the degree of deviation and the columellar-labial angle. Conclusion: The post-operative anthropometric results were consistent with the study subjects, mainly saddle deformity and aesthetic significance.

Key words; posttraumatic nasal deformities; saddle nose; augmentation rhinoplasty

\section{I. ĐẶT VẤN ĐỀ}

Mũi là cơ quan quan trơng với nhiều chức năng: hô hấp, khứu giác, hỗ trợ phát âm...và có ý nghĩa đặc biệt về thẩm mỹ. Gãy xương chính mũi chiếm hơn $40 \%$ tổng số gãy xương vùng mặt ở người trưởng thành ${ }^{1}$. Trong rất nhiều trường hợp tổn thương xương mũi thường bị bỏ sót khi chẩn đoán do không phát hiện kịp thời, do ưu tiên các chấn thương khác, hoặc do không thể can thiệp hoàn chỉnh ngay thì đầu do xương gãy nát vụn hoặc quá phức tạp. Sau gãy, xương chính mũi nhanh liên lại ít ảnh hưởng đến chức năng sống nên chỉ khi hình thành di chứng làm ảnh hưởng đến chất lượng sống của người bệnh 
gây tâm lý tự ti, mặc cảm về ngoại hình... chúng mới được quan tâm. Lúc này, xử trí biến dạng, lệch vẹo sống mũi ở giai đoạn muộn và di chứng thường rất khó khăn do các mảnh xương dễ bị tiêu, thay đổi kích thước và hình dáng nên không thể sắp xếp lại cho đúng hình thể của mũi, cũng như việc cố dịnh lại các mảnh xương đó cũng không dễ dàng ${ }^{2}$. Trên thế giới có rất nhiều nghiên cứu của các tác giả về điều trị biến dạng mũi di chứng chấn thương ${ }^{2-4}$. Tại Việt Nam, số lượng bệnh nhân chấn thương hàm mặt cao nhưng chỉ mới có vài báo cáo lẻ tẻ về điều trị chấn thương xương chính mũi. Chính vì vậy, chúng tôi thực hiện nghiên cứu này với mục tiêu "Đánh giá kết quả phẫu thuật điều trị biến dạng tháp mũi do di chứng chấn thương".

\section{II. Đốl TƯỢNG VÀ PHƯƠNG PHÁP NGHIÊN CỨU}

2.1 Đối tượng nghiên cứu: 20 bệnh nhân được chẩn đoán biến dạng tháp mũi di chứng chẩn thương điều trị nội trú tại bệnh viện Trung Ương Quân Đội 108 từ tháng 7/2017 đến tháng $8 / 2021$.

Tiêu chuẩn lựa chơn bênh nhân.Bệnh nhân được chẩn đoán biến dạng tháp mũi di chứng chấn thương trên 3 tháng bằng khám lâm sàng và chụp phim (X- quang hoặc $\mathrm{CT}$ ). Được can thiệp phẫu thuật tạo hình biến dạng tháp mũi và tự nguyên tham gia nghiên cứu.

Tiêu chuân loại trư. Một trong các tiêu chuẩn sau: BN có dị tật bẩm sinh gây biến dạng mũi trước khi chấn thương; $B N$ có vết thương phần mềm vùng mũi nhưng không gây biến dạng tháp mũi; $B N$ có biến dạng tháp mũi do bệnh lý; BN có các chống chỉ định phẫu thuật (theo tiêu chuẩn ngoại khoa chung); BN có biến dạng mũi di chứng chấn thương nhưng yêu cầu quá mức hoàn hảo hay có nghi ngờ mắc bệnh tâm thần hoặc bệnh nhân không hợp tác.

2.2 Thiết kế nghiên cứu: mô tả chùm ca bệnh cắt ngang.

2.3 Các chỉ số đánh giá cải thiện kết quả sau phẫu thuật

- Các chỉ số đo lường được đánh giá trước và sau phẫu thuật 3 tháng gồm:

(1) Độ lệch vẹo mũi ; (2) Tỷ lệ của hình chiếu đầu mũi/ chiều dài sống mũi;

(3) Góc trụ mũi - môi; (4) Góc mũi - trán.

- Bảng kiểm ROE (dịch sang tiếng Việt) để đánh giá độ hài lòng của bệnh nhân sau phẫu thuật.

\section{KẾT QUẢ NGHIÊN CỨU VÀ BÀN LUÂ̂N 3.1 Đăc điểm chung}

- Tuổi: Tuổi nhỏ nhất là 17 tuổi, lớn nhất là 46 tuổi, trung bình là $31.15 \pm 8.46$ tuổi. Nhóm tuổi từ 20-30 chiếm tỉ lệ cao nhất (45\%). Kết quả này tương tự nghiên cứu của các tác giả Trần Thị Phương $61,1 \%{ }^{5}$, Bùi Duy Vũ $68,1 \%^{6}$. Lý do được đưa ra là do đây là nhóm tuổi lao động chính và có nhu cầu làm đẹp cao.

- Giới: Tỉ lệ nam/nữ là 13/7 = 1,86

- Nguyên nhân gây chấn thường: gặp nhiều nhất là tai nạn giao thông (60\%),

ít gặp đánh nhau và tai nạn thể thao.

- Tất cả các bệnh nhân đều phấu thuật vì lý do thẩm mỹ, trong đó có $35 \%$ BN có mục đích phẫu thuật để cải thiện thêm cả về chức năng mũi nhiều nhất là ngạt mũi (30\%).

- Thời gian phẫu thuật sau chấn thương dài nhất là 20 năm, ngắn nhất là 3 tháng. Trong đó phẫu thuật sau chấn thương từ 3 - 6 tháng chiếm tỉ lệ thấp (5\%).

\subsection{Phân loại biến dạng mũi trước phẫu} thuật

Bảng 1: Phân loại biến dạng mũi trước phẫu thuật $(N=20)$

\begin{tabular}{|c|c|c|}
\hline Loại biến dạng & $\mathbf{n}$ & $\mathbf{\%}$ \\
\hline Biến dạng mũi lệch vẹo đơn thuần & 4 & 20 \\
\hline $\begin{array}{c}\text { Biến dạng mũi hình yên ngựa } \\
\text { (sập lõm) đơn thuần }\end{array}$ & 11 & 55 \\
\hline Biễn dạng mũi lệch vẹo kèm sập lõm & 5 & 25 \\
\hline
\end{tabular}

Trong nghiên cứu của chúng tôi biến dạng mũi hình yên ngựa $(80 \%)$ chiếm tỉ lệ cao hơn biến dạng mũi lệch veo (45\%). Kết quả trên có sự khác biệt với các tác giả Bùi Duy Vũ ${ }^{6}$ và Trần Thị Phương ${ }^{5}$ với tỉ lệ biến dạng mũi lệch vẹo (52,8\% và $72,22 \%)$ cao hơn biến dạng sập lõm sông mũi $(19,6 \%$ và $47,22 \%)$. Sự khác biệt này có thể giải thích do tiêu chí và thời điểm lựa chọn bệnh nhân khác với chúng tôi. Hơn nữa, biển dạng hình yên ngựa dễ bị bỏ qua ngay sau chấn thương do vùng mũi còn sưng nề khó đánh giá. Biến dạng này hay được phát hiện một thời gian dài sau chấn thương.

2.3 Đánh giá kết quả phẫu thuật tạo hình biến dạng tháp mũi di chứng chấn thương

- Các kỹ thuật thực hiện trong PT tạo hình mũi di chứng chấn thương

Bảng 2: Các kỹy thuật thức hiện trong PT tạo hinh mũi di chứng chấn thương ( $N=20)$

\begin{tabular}{|c|c|c|c|}
\hline \multicolumn{2}{|r|}{ Các loại KT } & n & $\%$ \\
\hline \multirow{4}{*}{$\begin{array}{l}\text { Chỉnh } \\
\text { hình } \\
\text { xương } \\
\text { mũi }\end{array}$} & Cắt xương & 1 & 5 \\
\hline & Mài gồ xương & 8 & 40 \\
\hline & Cắt xương và mài gồ xương & 3 & 15 \\
\hline & Không tạo hình & 8 & 40 \\
\hline \multirow{3}{*}{$\begin{array}{l}\text { Tạo } \\
\text { hình } \\
\text { độn }\end{array}$} & Không dùng & 3 & 15 \\
\hline & Sụn vách ngăn & 2 & 10 \\
\hline & Sụn sườn & 4 & 20 \\
\hline
\end{tabular}




\begin{tabular}{|c|c|c|c|c|}
\hline sống & tự thân & Nghiền nhỏ & 6 & 30 \\
\cline { 3 - 4 } mũi & & Kết hợp & 5 & 25 \\
\hline Tạo & \multicolumn{2}{|c|}{ Không tạo hình } & 5 & 25 \\
\cline { 2 - 4 } hình \\
\cline { 2 - 4 } đầu \\
\cline { 2 - 4 } mũi & \multicolumn{2}{|c|}{ Mảnh ghép trụ mũi } & 3 & 15 \\
\cline { 2 - 4 } & \multicolumn{2}{|c|}{ Khâu liên vòm } & 1 & 5 \\
\hline
\end{tabular}

Các kỹ thuật thực hiện trong nghiên cứu của chúng tôi gồm:

- Chỉnh hình xương mũi: kỹ thuật cắt xương + mài gồ chiếm $60 \%$ trong đó chủ yếu là kĩ thuật mài gồ xương. Kết quả trong nghiên cứu của chúng tôi gặp nhiều hơn các tác giả Bùi Duy Vũ $(47.1 \% \text { kỹ thuật cắt xương })^{6}$ và Yong-Ha $\operatorname{Kim}^{7}$ (27,5\% mài gồ xương).

- Tạo hình độn sống mũi: Bệnh nhân độn sống mũi trong nghiên cứu của chúng tôi $85 \%$ cao hơn tác giả Bùi Duy Vũ $64.7 \%$ do biến dạng mũi hình yên ngựa (sập lõm) trong nghiên cứu của chúng tôi chiếm đa số. Vật liệu sử dụng để độn sống mũi trong nghiên cứu của chúng tôi chủ yếu sựn sườn tự thân $75 \%$ khác với các tác giả Nguyễn Thành Nhân ${ }^{8} 100 \%$ vật liệu nhân tạo kết hợp sụn vành tai và sụn vách ngăn; Hoàng Văn Hồng $100 \%$ silicone hoặc sụn vành tai; Bùi Duy Vũ $67,05 \%$ sụn vành tai và $9,8 \%$ vật liệu nhân tạo. Sự khác biệt trên là do đối tượng nghiên cứu của các tác giả trên là bệnh nhân không có chấn thương hoặc ngay sau chấn thương nên cấu trúc tháp mũ̃i dễ dàng chỉnh lại và lượng vật liệu độn sống mũi không lớn nên ưu tiên sử dụng các vật liệu nhân tạo hoặc sụn vành tai, vách ngăn. Trong khi nghiên cứu của chúng tôi chủ yếu là các dị dạng hình yên ngựa nên cần một số lượng lớn chất liệu tạo hình. Điều này lý giải cho con số $75 \%$ bệnh nhân trong nghiên cứu của chúng tôi sử dụng sụn sườn trong phẫu thuật. Tác giả Balaji S.M nhận thây rằng sụn mêm có tỉ lệ cong vênh $(35,5 \%)$ cao hơn sụn cứng $(9,1 \%)^{10}$. Và theo tác giả Suh M.K để giảm thiểu sự cong vênh của sụn sườn, khi cắt gọt sụn sườn nên lấy phần lõi sụn hoặc bằng cách cắt gọt mảnh ghép sao cho các lực biến dạng được cần bằng thông qua đường cắt ngang ${ }^{3}$.

- Tạo hình đâu mũi: Không tạo hình chỉ chiếm $25 \%$, tạo hình chủ yếu là tạo độ nhô bằng sụn nghiền $55 \%$. Các kỹ thuât khác giúp cải thiện độ nhô đầu mũi bao gồm: mảnh ghép trụ mũi 15\%; khâu liên vòm $5 \%$. Kết quả trong nghiên cứu của chúng tôi tương tự tác giả Nguyễn Thành Nhân ${ }^{8} 98,8 \%$. Lý do được đưa ra là do việc tạo hình đầu mũi liên quan đến nhu cầu thẩm mỹ của bệnh nhân, điêu này cũng phù hợp với $100 \%$ bệnh nhân nhập viện vì nhu cầu thẩm mỹ trong nghiên cứu của chúng tôi.

- Các kỹ thuật khác kèm theo: chỉnh hình vách ngăn $45 \%$; tạo hình ổ mắt $20 \%$; tạo hình kéo dài trụ mũi $10 \%$, thu gọn cánh mũ̃i $10 \%$ giúp phẫu thuật đạt được hiệu quả cao nhất cả về thẩm mỹ và chức năng.

- Đánh giá sự thay đổi chỉ số đo trước và sau PT 3 tháng

Bảng 3: Kiềm định T-test ghép cặp các chỉ số đo lường trước và sau PT 3 tháng ( $N=20$, $p=0,01$ )

\begin{tabular}{|c|c|c|c|c|c|}
\hline \multicolumn{2}{|l|}{ Chỉ số } & Trung bình (độ) & SD & $\mathbf{t}$ & $\mathbf{p}$ \\
\hline \multirow{2}{*}{ Độ lệch vẹo mũi } & Trước PT & 4.45 & 7.82 & \multirow{2}{*}{2.490} & \multirow{2}{*}{0.22} \\
\hline & Sau PT & 0.65 & 1.63 & & \\
\hline \multirow{2}{*}{$\begin{array}{l}\text { Tỷ lệ của hình chiếu đầu } \\
\text { mũi/ chiều dài mũi }\end{array}$} & Trước PT & 0.638 & 0.094 & \multirow{2}{*}{-6.236} & \multirow{2}{*}{0.000} \\
\hline & Sau PT & 0.749 & 0.764 & & \\
\hline \multirow{2}{*}{ Góc trụ mũi - môi } & Trước PT & 131 & 11 & \multirow{2}{*}{19} & \multirow{2}{*}{0.110} \\
\hline & Sau PT & 136 & 10 & & \\
\hline \multirow{2}{*}{ Góc mũi - trán } & Trước PT & 96 & 14 & \multirow{2}{*}{19} & \multirow[b]{2}{*}{0.006} \\
\hline & Sau PT & 104.3 & 9.5 & & \\
\hline
\end{tabular}

Các chỉ số nhân trắc học trước và sau phẫu thuật trong nghiên cứu của chúng tôi cho thây có sự cải thiện đáng kể về tỷ lệ hình chiếu đầu mũi/ chiều dài mũi trung bình từ 0.638 trước phẫu thuật tăng lên 0.749 sau phẫu thuật và góc mũi trán từ $96^{\circ}$ trước phẫu thuật lên $104.3^{\circ} \mathrm{sau}$ phẫu thuật (có ý nghĩa thống kê với $p<0,01$ ). Còn lại các chỉ số độ lệch vẹo mũi và góc trụ mũi môi có sự cải thiện nhưng thay đổi không đáng kể. Kết quả trong nghiên cứu của chúng tôi khác tác giả Yong H.K với sự cải thiện có ý nghĩa thống kê ở 2 chỉ số độ lệch vẹo và góc mũi trán $(p<0,01)^{7}$. Nguyên nhân có thể kể đến thứ nhất là do đối tượng nghiên cứu của tác giả không chỉ bao gồm chấn thương mà còn do nhiều nguyên nhân khác như dị dạng bẩm sinh... Thứ hai là do đối tượng nghiên cứu của tác giả $100 \%$ là mũi lệch vẹo trong khi nghiên cứu của chúng tôi chủ yếu là dị dạng mũi yên ngựa $(80 \%)$, tỉ lệ mũi lệch veo chỉ chiếm $45 \%$ nển sư cải thiên sau phẫu thuật của chúng tôi về 2 chỉ số tỉ lệ hình chiếu đầu mũi/ chiều dài mũi và góc mũi trán là 
hợp lý và có ý nghĩa cải thiện về mặt thẩm mỹ cho bệnh nhân.

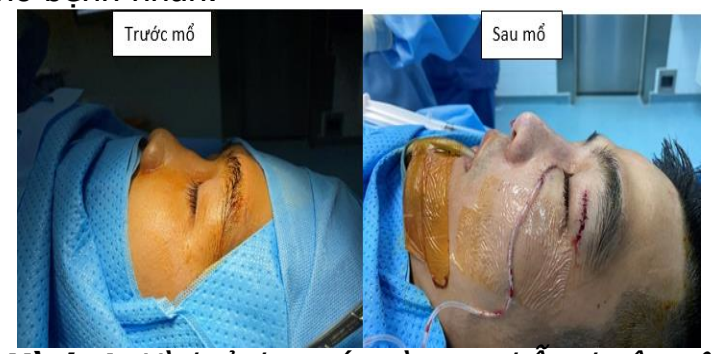

Hinh 1. Hinh ảnh trước và sau phâuu thuật mũi hinh yên ngựa (bệnh nhân T.V.H mã bệnh án: 20783759)

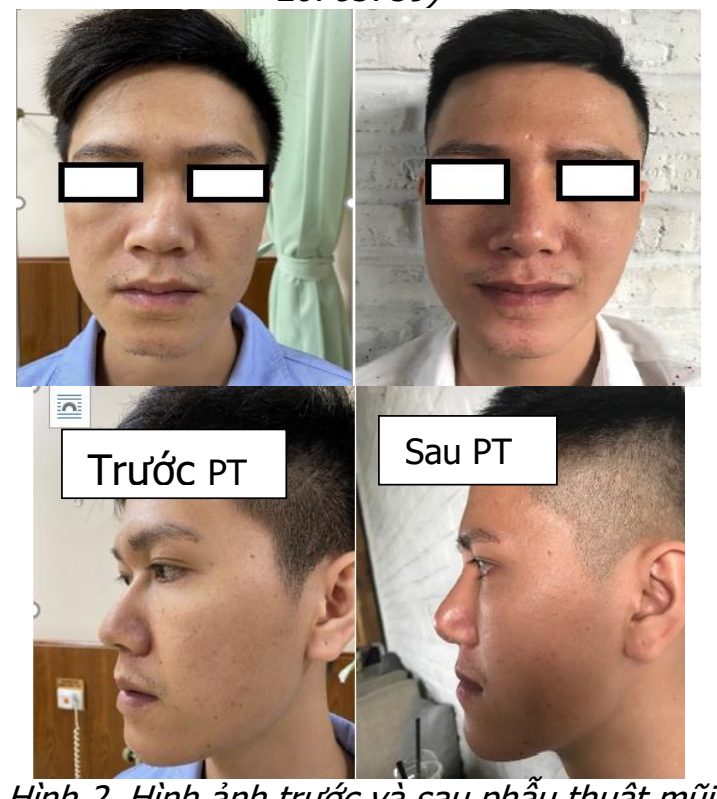

Hình 2. Hình ảnh trước và sau phẫu thuật mũi lệch vẹo (bệnh nhân N.N.Đ mã bệnh án 20720787)

- Đánh giá mức đô hài lòng của bênh nhân sau PT 3 tháng bằng bảng kiểm ROE.

Bảng 4: Độ hài lòng của bệnh nhân sau PT $(N=20)$

\begin{tabular}{|c|c|c|}
\hline Mức độ hài lòng & $\mathbf{n}$ & $\mathbf{\%}$ \\
\hline Rất hài lòng (Excellent) & 8 & 40 \\
\hline Khá hài lòng (Good) & 9 & 45 \\
\hline $\begin{array}{c}\text { Hài lòng nhưng còn ít } \\
\text { khuyết điểm (Fair) }\end{array}$ & 3 & 15 \\
\hline Không hài lòng (Poor) & 0 & 0 \\
\hline $\mathrm{N}$ & 20 & 100 \\
\hline
\end{tabular}

Trong nghiên cứu của chúng tôi 100\% bệnh nhân hài lòng với kết quả sau phẫu thuật, chỉ có $15 \%$ bênh nhân tuy hài lòng nhưng vẫn còn môt số ít khuyết điểm muốn cải thiện hơn nữa. Kết quả trên cũng tương tự tác giả Hyun M.S với $97,8 \%$ hài lòng ${ }^{4}$; Nguyễn Thành Nhân ${ }^{8} 100 \%$ hài lòng.

\section{KẾT LUẬN}

Qua nghiên cứu 20 trường hợp điêu trị biến dạng mũi di chứng sau chấn thượng tại bệnh viện Trung Ương Quân Đội 108 chúng tôi rút ra những đặc điểm sau:

- Tuổi trung bình 31,56; gặp chủ yếu ở nhóm tuổi từ 20-30. Biến dạng mũi hình yên ngựa (80\%) chiếm tỉ lệ cao hớn biến dạng mũi lệch vẹo (45\%). Kỹ thuật tạo hình mũi di chứng sau chấn thương chủ yếu gồm chỉnh hình xương mũi $60 \%$, tạo hình độn sống mũi $85 \%$ trong đó chủ yếu dung sụn sườn tự thân $75 \%$, tạo hình đâu mũi 75\% trong đó chủ yếu là tạo độ nhô bằng sụn nghiền $55 \%$.

- Sau phẫu thuật có sự cải thiện đáng kể tỷ lệ hình chiếu độ nhô đâu mũi/ chiều dài sống mũi trung bình từ 0.638 tăng lên 0.749 và góc mũi trán từ $96^{\circ}$ lên $104.3^{\circ}$ (có ý nghĩa thống kê với $p<0,01)$. Các chỉ số độ lệch vẹo và góc trụ mũimôi có sự cải thiện nhưng thay đổi không đáng kể. $100 \%$ bênh nhân hài lòng với kết quả sau phẫu thuật (đánh giá bằng bảng kiểm ROE dịch sang tiếng Việt).

\section{TÀI LIÊU THAM KHẢO}

1. Hung $T$, Chang $W$, Vlantis $A C$, Tong MCF, van Hasselt CA. Patient Satisfaction After Closed Reduction of Nasal Fractures. ARCH FACIAL PLAST SURG. 2007;9:4.

2. Suh MK, Jeong E. Correction of deviated nose. Arch Craniofacial Surg. 2018;19(2):85-93. doi: 10.7181/acfs.2018.01914

3. Suh MK. Atlas of Asian Rhinoplasty. Springer Nature Singapore; 2018.

4. Hyun SM, Jang YJ. Treatment Outcomes of Saddle Nose Correction. JAMA Facial Plast Surg. 2013;15(4):280-286.

5. Trân Thị Phương. Nghiên cứu đặc điểm lâm sàng và chụp cắt lớp vi tính của chấn thương tháp mũi. Luận văn thạc sỹ, Đại học Y Hà Nội; 2009.

6. Bùi Duy Vũ். Nghiên cứu đặc điểm hình thái lâm sàng của dị hình tháp mũi mắc phải và biện pháp can thiệp. Luân văn thac sỹ, Đai học Y Hà Nội; 2011.

7. Kim Y-H, Jung CY, Chung KJ, Lee JH, Kim TG. A Systematized Strategy in Corrective Rhinoplasty for the Asian Deviated Nose. Ann Plast Surg. 2017;79(1):7-12.

8. Nguyễn Thành Nhân. Nghiên cứu tạo hình nâng sống mũi bằng mô tự thân phối hợp với vật liệu nhân tạo. Luận án tiến sỹ, Viện nghiên cứu khoa học Y Dược lậm sàng 108; 2016.

9. Hoàng Văn Hồng, Pham Thị Bích Đào, Nguyển Doãn Tuất, Dương Huy Lương. Đánh giá kết quả tạo hình lại sống mũi cấu trúc sau chấn thương. Tạp Chí Y Học Việt Nam. 2018;5(2):1-3.

10. Balaji S.M. Costal cartilage nasal augmentation rhinoplasty: Study on warping. Ann Maxillofac Surg. 2013;3(1):20-24. 